\title{
PERANCANGAN SISTEM APLIKASI PENGGAJIAN KARYAWAN PADA YAYASAN AL-AKMAL
}

\author{
Alif Muhammad Bayhaqi ${ }^{1}$, Sri Mardiyati ${ }^{2}$, Ulfa Pauziah ${ }^{3}$ \\ Program Studi Teknik Informatika, Fakultas Teknik dan Ilmu Komputer, \\ Universitas Indraprasta PGRI \\ Jalan Raya Tengah No 80, Kelurahan Gedong, Pasar Rebo, Jakarta Timur \\ bayhaqialif8@gmail.com ${ }^{1}$, srimardiyati05@gmail.com ${ }^{2}$,pelangi_ulfa@yahoo.com³
}

\begin{abstract}
Abstrak
Tujuan dari penelitian ini adalah untuk mengetahui sistem penggajian yang digunakan saat ini pada yayasan Al-Akmal. Untuk mengetahui kekurangan yang ada pada sistem penggajian dan merancang sistem penggajian terkomputerisasi yang sesuai di Yayasan Al-Akmal sehingga dapat membuat laporan penggajian yang akurat dan efisien. Metode penelitian yang digunakan pada perancangan sistem informasi penggajian ini adalah studi lapangan yaitu dengan pengamatan langsung, wawancara dengan pihak terkait dan juga melakukan dokumentasi untuk mendapatkan informasi yang dibutuhkan. Selain itu peneliti juga melakukan penelitian dengan menggunakan metode kepustakaan berdasarkan referensi dari berbagai diskusi serta berbagai media yang memuat informasi mengenai segala sesuatu yang menyangkut informasi yang dibutuhkan, analisa kebutuhan, perancangan, implementasi, pengkodean dan pengujian. Setelah dilakukan pengujian secara implementasi ternyata aplikasi ini dapat membantu memenuhi kebutuhan akan suatu proses penyimpanan data-data karyawan Yayasan Al-Akmal serta dapat membuat sistem yang lebih baik dalam hal penggajian.
\end{abstract}

Kata Kunci: Perancangan, Aplikasi, Penggajian

\section{Abstract}

The purpose of this research is to find out the payroll system used today at the Yayasan Al-Akmal. To find out the short comings that exist in the payroll system and design a computerized payroll system that is appropriate at Yayasan al-Akmal, so as to make accurate and efficient payroll reports. The research method used in the design of payroll information system is field study, namely by direct observation, interview with related parties and also doing documentation to get the required information. In addition, the author also conducted research using literature methods based on references from various discussions as well as various media containing information about everything related to the required information, needs analysis, design, implementation, coding and testing. After the implementation of the test, it turns out that this application can help meet the needs of a process of storing the data of Yayasan Al-Akmal. employees and can create a better system in terms of payroll.

Keywords: Design, Aplication, Payrol.

\section{PENDAHULUAN}

Pada zaman era globalisasi saat ini kebutuhan akan teknologi informasi semakin meningkat, hal ini disebabkan oleh semakin berkembangnya teknologi informasi disalah satu bagiannya yaitu software perangkat lunak. Kebutuhan akan software ini ditandai dengan semakin banyaknya jenis dan macam-macam software yang ditawarkan kepada konsumen baik untuk perorangan maupun perusahaan, menurut (Pramana, 2010) aplikasi adalah suatu unit perangkat lunak yang dibuat untuk melayani kebutuhan akan beberapa aktivitas seperti sistem, game, pelayanan masyarakat, periklanan atau semua proses yang dilakukan manusia. Sedangkan menurut (Rizky Dhanta, 2009) aplikasi (application) adalah misalnya Microsoft Word dan Microsoft Excel. Software atau yang termasuk kedalamnya yaitu program aplikasi, digunakan pada saat ini oleh sebagian besar perusahaan atau yayasan untuk dapat membantu pekerjaan para pegawai dalam pengolahan datadata maupun dalam proses perhitungannya seperti gaji, penjualan, pembelian, dan sebagainya. Dalam sebuah yayasan pasti memiliki banyak karyawan yang mendukung kelancaran usahanya 
serta memebrikan kontribusi yang besar bagi yayasan, dari hasil kontribusi tersebut karyawan akan mendapat upah sebagai balas jasa dan telah ditentukan oleh yayasan.

Upah atau gaji merupakan hal yang sangat penting bagi seorang karyawan sebagai motivator sehingga mereka dapat lebih berprestasi dan memberikan output yang lebih baik bagi yayasan salah satunya adalah Yayasan Al-Akmal, maka dibuatlah program aplikasi ini untuk mempermudah yayasan dalam hal perhitungan gaji yang lebih terkomputerisasi. Yayasan Al-Akmal merupakan salah satu yayasan yang bergerak dibidang pendidikan Al-Qur'an dan membantu warga binaan yang kekurangan, dalam pekerjaannya Yayasan Al-Akmal membrikan guru atau tenaga-tenaga kerja yang sebelumnya sudah mendapatkan pelatihan-pelatihan khusus sebelum terjun mengajar atau membina. Pada awalnya Yayasan Al-Akmal untuk menyelesaikan pekerjaannya dalam penggajian menggunakan program Microsoft Excel yang dimulai dari pengisian data penggajian sampai pencetakan laporan. Disarankan agar yayasan menerapkan sistem informasi yang terkomputerisasi salah satunya aplikasi berbasis Java. Oleh karena itu peneliti tertarik untuk membuat "Perancangan Sistem Aplikasi Penggajian Karyawan pada Yayasan Al-Akmal". Peneliti berharap semoga aplikasi program ini dapat membantu dalam mengontrol dan mendukug keseluruhan aktifitas dan kinerja sumber daya manusia dengan harapan mempermudah yayasan dalam memproses gaji/upah karyawan dengan cepat, tepat dan akurat.

\section{PENELITIAN RELEVAN}

Dalam rangka mendapatkan hasil penelitian yang baik, selain melakukan penelitian secara langsung peneliti juga melakukan kajian pustaka. Dari hasil penelitian yang telah dilakukan. Beberapa hasil acuan yang menjadi acuan adalah:

Penelitian dari (Alfred Yulius, 2016) yang berjudul "Analisis Dan Perancangan Sistem Informasi Penggajian Pada TK-SD Bruder Nusa Indah Pontianak". Pengolahan data gaji karyawan tentu menjadi salah satu hal penting dalam kegiatan dunia pendidikan, sehingga membutuhkan suatu sistem informasi yang dapat melakukan fungsi pengolahan data khususnya gaji karyawan secara efektif dan efisien. Solusi alternatif yang diusulkan disni adalah perlu adanya sistem informasi penggajian yang dapat mengolah data gaji karyawan TK-SD Bruder Nusa Indah Pontianak secara cepat, tepat, dan lengkap dengan efesien waktu dalam pengerjanya.

Penelitian dari (Wulandari, Giyantono, \& Gunawan, 2017) yang berjudul "Rancang Bangun Penggajian Karyawan Berbasis Web Pada PT.Surganya Motor Indonesia". Metode yang digunakan dalam penelitian ini yaitu metode pengumpulan data diantaranya, wawancara, observasi, dan studi pustaka. Metode analisa yang digunakan yaitu analisa SWOT, sedangkan metode perancangan menggunakan UML. Metode pengujiannya menggunakan metode black box.

Penelitian dari (Indria Hangga Rani, 2015) yang berjudul "Rancang Bangun Sistem Informasi Akutansi Penggajian Karyawan Dan Guru Tetap (Studi Pada Yayasan Pendidikan Yampi Jakarta Utara)". Hasil dari penelitian ini adalah rancangan-rancangan sistem berupa diagram rancangan sistem dan program penggajian. Penelitian ini dibatasi sampai tahap construction pada metodolodi rekayasa perangkat lunak dan penggujian menggunakan metode blackbox testing dengan yayasan Pendidikan Yapim di Jakarta Utara sebagai sample pengambilan data.

Penelitian dari (Azmi, 2015) yang berjudul "Rancang Bangun Sistem Informasi Penggajian Honorarium Guru Dan Pegawai Yayasan Nurul Huda Kecamatan Batang Tuaka”. Pada penelitian ini metode yang digunakan untuk melakukan pengembangan sistem yaitu dengan metode SDLC (System Development Life Cicle) sehingga dalam pengembangannya dapat dilakukan dengan terstuktur. Tujuan dari penelitian ini adalah merancang sistem informasi penggajian honorarium guru dan pegawai pada Yayasan Nurul Huda Kec. Batang Tuaka, sehingga dapat memberikan kemudahan kepada pengguna untuk mengetahui data penggajian guru dan pegawai, memudahkan bagian keuangan dalam mengolala data penggajian.

Penelitian dari (Aruan \& Adnyani, 2018) yang berjudul "Perancangan Sistem Informasi Penggajian Pegawai Berbasis Java Disekolah Menengah Kejuruan Nusantara Wisata Respati”. Penelitian ini menghasilkan sistem, Sistem ini dirancang untuk menangani traksaksi perhitungan gaji pengawai dan pembayaran dan dapat menjamin validiitas, otorisasi kelengkapan, klasifikasi penilaian, ketepatan waktu dari setiap traksaksi penggajian. 
Penelitian dari (Meritasari \& Sai, 2014) yang berjudul "Analisis Sistem Akutansi Penggajian Karyawan Dalam Upaya Mendukung Pengendalian Intern”. Tujuan dari penelitian ini adalah untuk mengetahui sistem akuntansi penggajian karyawan pada PT PLN (Persero) Udiklat Pandaan dalam upaya mendukung pengendalian intern perusahaan dan untuk mengetahui pengendalian intern pada sistem akuntansi penggajian yang digunakan. Hasil penelitian menunjukkan bahwa berkaitan dengan fungsi-fungsi yang terkait sebaiknya untuk fungsi bagian pencatat waktu dibuat terpisah dari fungsi SDM.

\section{METODE PENELITIAN}

Menurut (Sukmadinata, 2009) menjelaskan bahwa penelitian dapat diartikan sebagai suatu proses pengumpulan dan analisis data yang dilakukan secara sistematis dan logis dengan menggunakan metode ilmiah untuk mencapai tujuan-tujuan tertentu. Metode penelitian yang digunakan adalah metode deskriptif yaitu metode yang hanya menggambarkan dan meringkaskan berbagai kondisi, situasi atau berbagai variable. Metode pengumpulan data yang dilakukan oleh peneliti untuk mendapatkan data-data serta informasi untuk mendukung penyempurnaan hasil dari penelitian ini antara lain :

1. Studi Pustaka

Metode ini dilakukan dengan mempelajari buku-buku perpustakaan, mencari infortmasi melalui internet serta peneliti mempelajari, menyimak dan mengambil kesimpulan dari data informasi melalui pustaka yang erat kaitannya dengan permasalahan yang dibahas. Metode ini juga dijadikan referensi dalam penelitian.

2. Studi Lapangan dilakukan dengan melihat langsung penerapan proses produksi dan pemensanan, dalam studi lapangan ini dipergunakan teknik pengumpulan data antara lain dengan cara:

a. Wawancara

Wawancara ini dilakukan untuk memperoleh data dari narasumber yaitu dari Bu Hikmawati, S.Pd sebagai bagian keuangan tentang Sistem Penggajian Karyawan pada Yayasan AlAkmal. Dalam penelitian ini peneliti menanyakan beberapa hal yang terkait dengan Sistem Penggajian pada Yayasan Al-Akmal. Metode ini digunakan untuk memperoleh informasi dan data statistik untuk membuat Perancangan Sistem Aplikasi Penggajian Karyawan pada Yayasan Al-Akmal.

b. Observasi

Peneliti mengaddakan praktek langsung ke yayasan guna proses Perancangan Sistem Aplikasi Penggajian Karyawan pada Yayasan Al-Akmal setiap bulannya. Dari hasil pembuatan laporan Penggajian tersebut akan menghasilkan data-data dan laporan yang lebih simple.

c. Sumber Data

Menurut (Zuldafrial, 2012) sumber data adalah subjek dari mana data dapat diperoleh. Metode dokumentasi ini digunakan untuk mendapatkan berbagai informasi dalam Perancangan Sistem Aplikasi Penggajian Karyawan pada Yayasan Al-Akmal yang berkaitan dengan variabel penelitian yang belum didapatkan dari hasil penelitian.

\section{HASIL DAN PEMBAHASAN}

Alternatif penyelesaian masalah yang peneliti usulkan, Untuk mendapatkan solusi permasalahan yang ada maka peneliti membuat suatu sistem yang akan membantu dalam menyelesaikan masalah tersebut, yaitu perancangan sistem aplikasi penggajian karyawan yag akan memudahkan dalam pengolahan data. Tujuan peneliti membangun suatu perancangan sistem aplikasi penggajian karyawan yaitu, perancangan sistem aplikasi pengolahan data yang terkomputerisasi sehingga mendapatkan data yang akurat, tepat dan cepat, Aplikasi yang user friendly yang dapat memudahkan pengguna aplikasi untuk menggunakan aplikasi tersebut. serta perancangan database untuk sistem pengolahan data agar tidak menggunakan media kertas lagi melainkan harddisk ataupun penyimpanan media elektronik lainnya seperti flashdisk. 


\section{Diagram Alir Data (DAD) Sistem yang Diusulkan (Diagram Konteks, Nol, Rinci) Diagram} Konteks

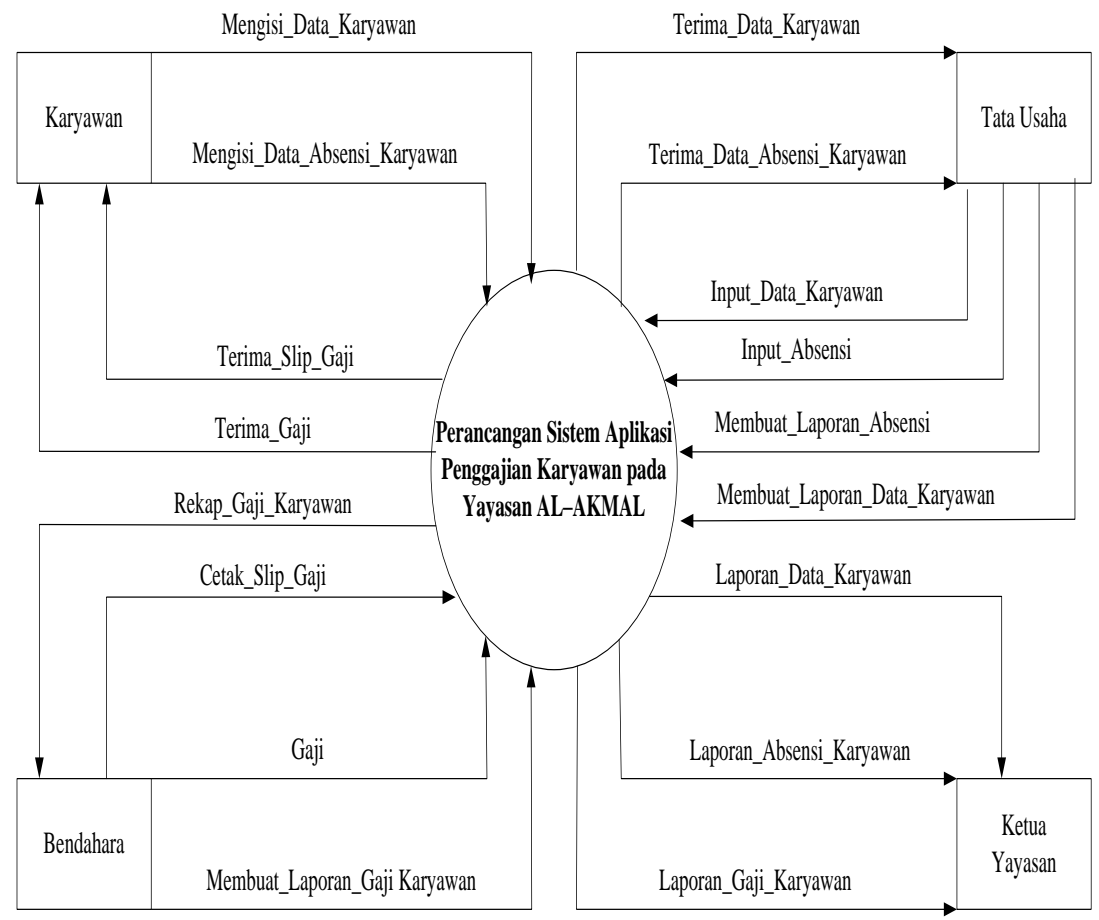

Gambar 1. Diagram Konteks yang Diusulkan

Pada diagram ini, berawal dari Karyawan yang mengisi biodata diri dan data absensi yang kemudian akan diinput ke aplikasi oleh tata usaha, setelah data disimpan pada databse, bendahara akan melakukan proses perhitungan gaji dengan mengambil data karyawan pada databse, setalah dilakukan perhitungan Karyawan akan menerima Gaji dan Slip Gaji yang dibuat oleh Bendahara. Setelah itu Tata Usaha akan membuat laporan Data Karyawan dan Data Absensi, sedangkan Bendahara akan membuat Laporan Gaji perbulan dan laporan gaji perdivisi, dan semua laporan akan diserahkan kepada Ketua Yayasan

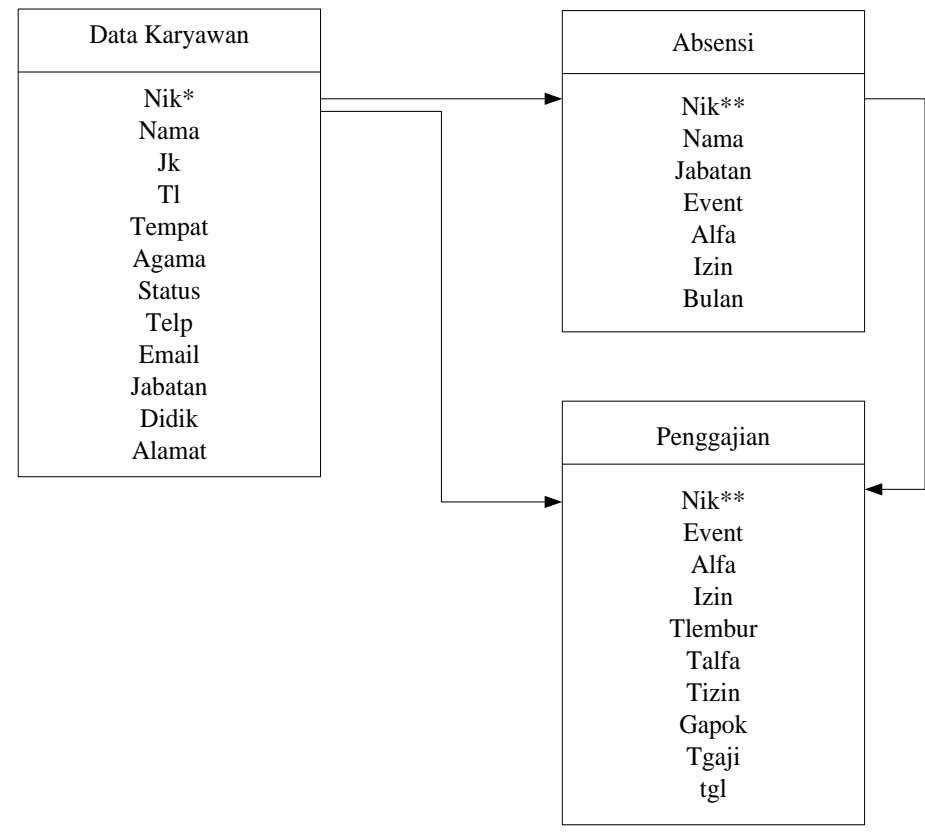

Gambar 2. Normalisasi Bentuk Ke-2 NF (2NF) 
Pada gambar diatas, ada bentuk normalisasi 2-NF dimana tabel Penggajain dibagi menjadi dua tabel yaitu tabel Absensi untuk olah data Absensi Karyawab dan Tabel Penggajian untuk proses penghitungan gaji karyawan, sehingga pada 2-NF terdapat 3 tabel dan seluruh tabel mengandung atribut NIK sebagai Primary Key atau penghubung.

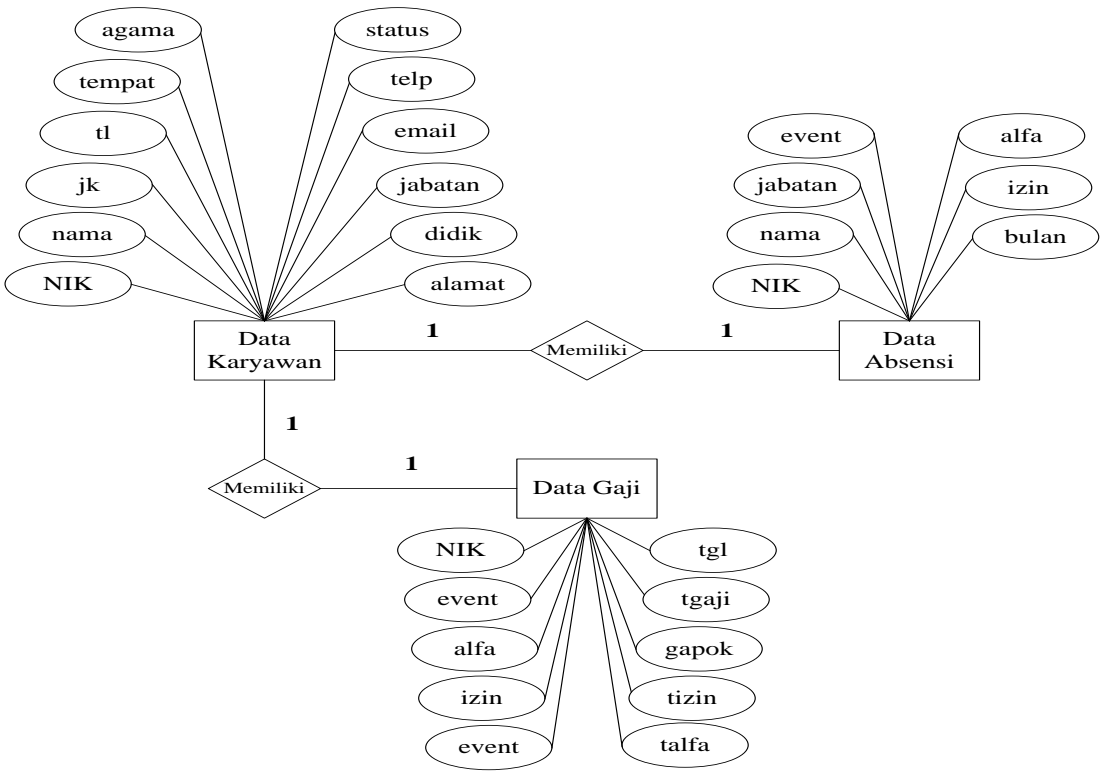

Gambar 3. ERD (Entity Relationship Diagram)

Pada gambar diatas menjelasakan 1 data Karyawan hanya memiliki 1 data Absensi dan 1 data Gaji, yang dimana atribut NIK menjadi penghubung dari seluruh entitas yang ada.

\section{Rancangan Tampilan Layar}

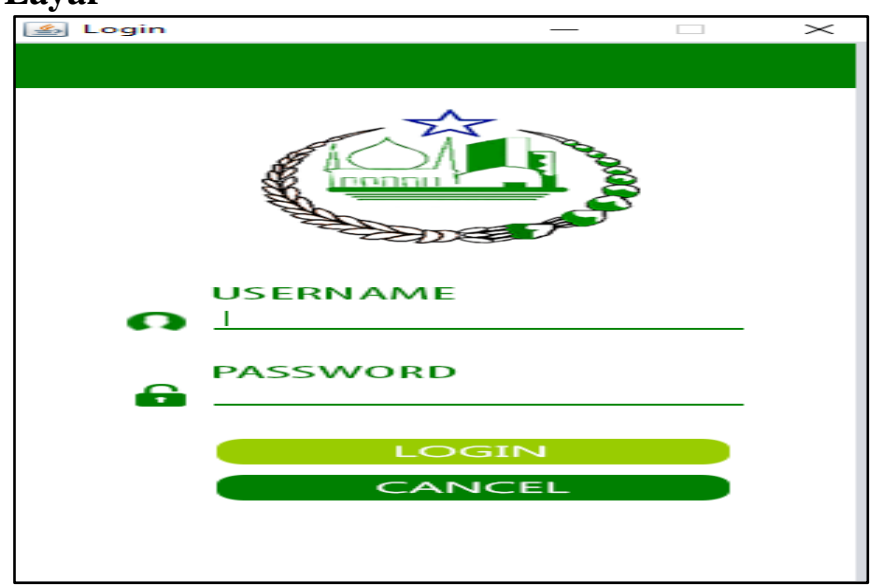

Gambar 5. Tampilan Layar Halaman Login

Tampilan ini terdapat pada awal program. Menu login digunakan sebagai kata kunci sebelum kita memasuki menu utama atau menu Reservasi. Agar tidak sembarangan orang dapat mengakses program ini. Sehingga dalam form menu kerahasiaanya dapat terjaga dengan baik. Pengguna atau user harus mempunyai akses berupa username dan password untuk dapat menggunakan aplikasi tersebut. 


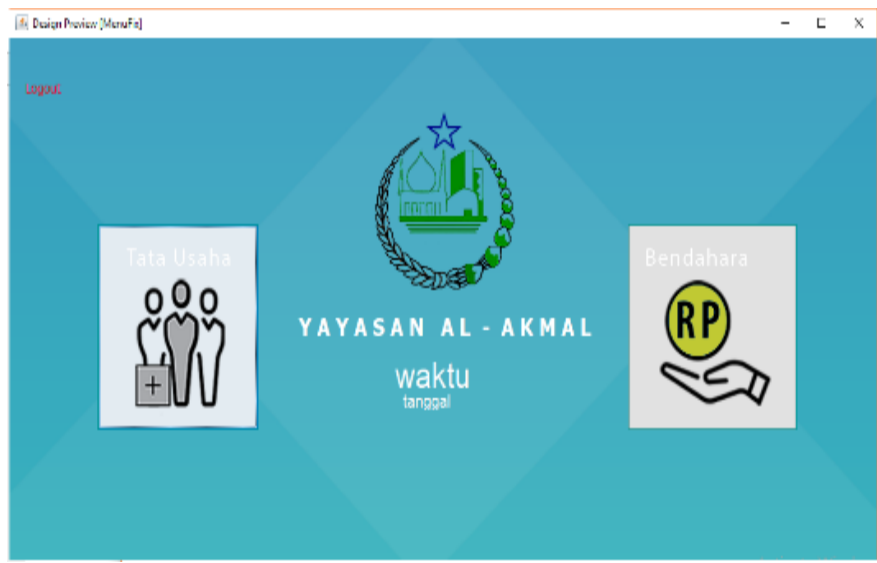

Gambar 6. Tampilan Layar Halaman Menu Utama

Tampilan layar Halaman Menu: pada halaman ini user dibedakan menjadi dua jenis akun yaitu sebagai Tata Usaha dan Bendahara, dimana masing-masing jenis akun hanya bisa mengakses menu yang sesuai dengan bagiannya, contoh bendahara tidak dapat mengakses menu tata usaha dan sebaliknya.

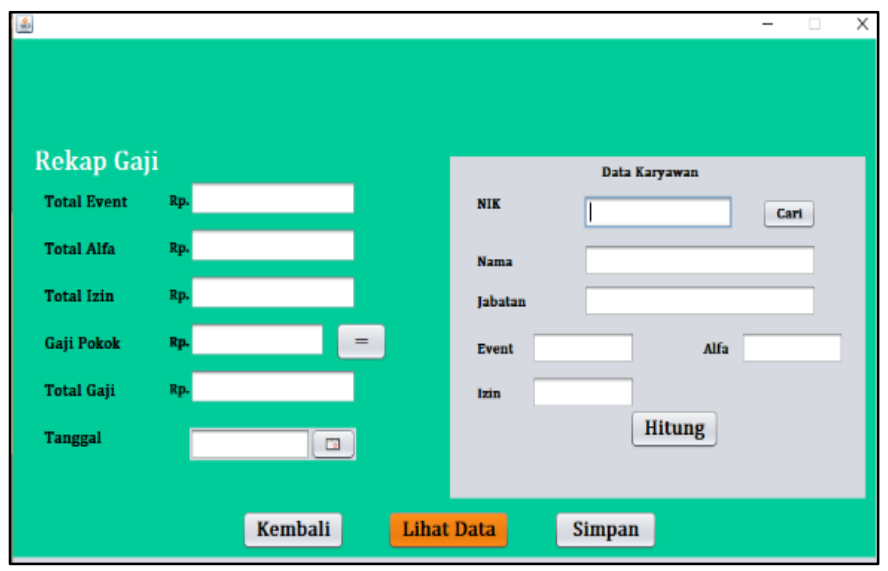

Gambar 7. Tampilan Layar Halaman Rekap Gaji

Halaman isi user bendahara akan melakukan proses perhitungan gaji karyawan berdasarkan data absensi karyawan yang sudah diinput oleh tata usaha.

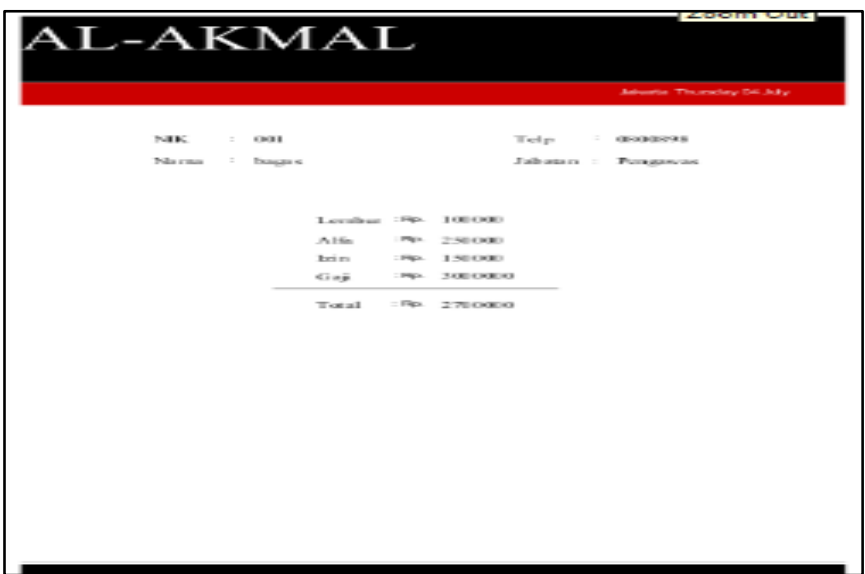

Gambar 8. Tampilan Slip Gaji 
Laporan ini dapat kita lakukan setelah kita menekan tombol cetak pada halaman menu rekap gaji. Laporan ini berisi Data nik, nama karyawan, tlpn, jabatan, lembur, alfa, izin dan gaji karyawan Yayasan Al-Kamal.

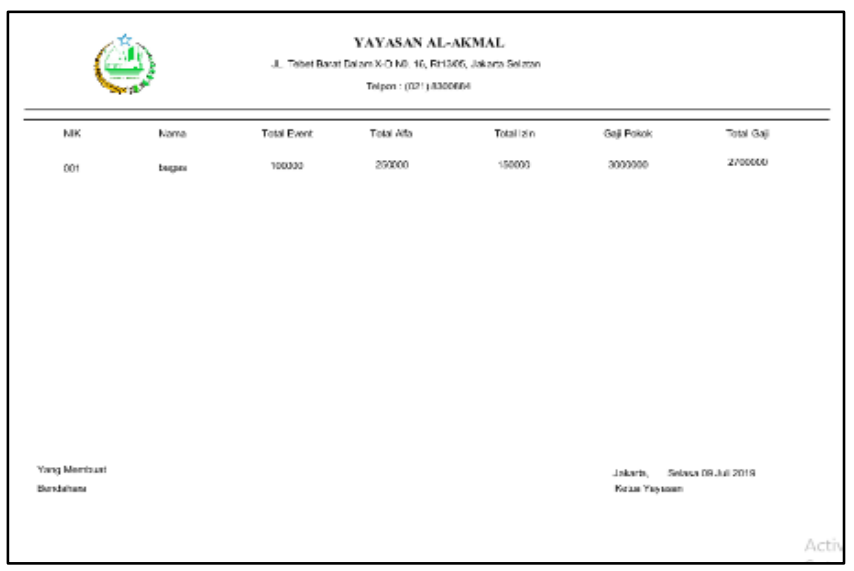

Gambar 16. Tampilan Laporan Data Gaji

Laporan ini dapat kita lakukan setelah kita menekan tombol cetak pada halaman menu laporan gaji karyawan. Laporan ini berisi Data nik, total event, total izin, total alfa, gaji pokok dan total gaji.

\section{SIMPULAN}

Dengan dibuatnya Aplikasi Penggajian pada Yayasan Al-Akmal, semua kegiatan yang berhubungan dengan penggajian dapat berjalan dengan baik dan lancar. Pada aplikasi ini, Tata Usaha dapat menangani pekerjaan penginputan data karyawan dengan cepat dan akurat serta dapat ter-update dengan mudah, dan Bendahara dapat mengolah gaji karyawan dengan mudah. Dengan adanya aplikasi ini diharapkan akan mempermudah kegiatan atau aktivasi pekerjaan yang memerlukan kecepatan dan ketepatan informasi. Kecepatan dan ketepatan informasi ini juga membutuhkan partisipasi aktif dari Tata Usaha dan Bendahara dalam menginput data dan mengolah gaji.

\section{DAFTAR PUSTAKA}

Alfred Yulius, A. (2016). Analisis Dan Perancangan Sistem Informasi Penggajian Pada TK-SD Bruder Nusa Indah Pontianak. Jurnal InTekSis, Vol 3 No.1, 9-16.

Aruan, M. C., \& Adnyani, L. P. W. (2018). Perancangan Sistem Informasi Penggajian Pegawai Berbasis Java Disekolah Menengah Kejuruan Nusantara Wisata Respati. Jurnal String, Vol. 3 No., 160-169.

Azmi, M. (2015). Rancang Bangun Sistem Informasi Penggajian Honorarium Guru Dan Pegawai Yayasan Nurul Huda Kecamatan Batang Tuaka. Jurnal SISTEMASI, Volume 4, 45 - 56.

Indria Hangga Rani, M. M. (2015). Pengaruh Penilaian Kinerja Terhadap Kinerja Karyawan Dengan Motivasi Sebagai Variabel Moderasi. Jurnal Akuntansi, Ekonomi Dan Manajemen Bisnis, 3, no, 164-170.

Meritasari, P., \& Sai, M. (2014). Analisis Sistem Akutansi Penggajian Karyawan Dalam Upaya Mendukung Pengendalian Intern. Jurnal Administrasi Bisnis (JAB), Vol. 9 No., 1-8.

Pramana, H. W. (2010). Definisi Aplikasi.

Rizky Dhanta. (2009). Pengantar Ilmu Komputer. Surabaya: INDAH.

Sukmadinata, N. S. (2009). Metode Penelitian Pendidikan. Bandung: Remaja Rosdakarya.

Wulandari, R., Giyantono, A., \& Gunawan, A. (2017). RANCANG BANGUN PENGGAJIAN KARYAWAN BERBASIS WEB PADA PT. SURGANYA MOTOR INDONESIA. CERITA, Vol 3 No 1, 27-35.

Zuldafrial, M. (2012). Penelitian Kualitatif. Surakarta: Yuma Pustaka. 